Phosphorus Research Bulletin Vol. 5 (1995), 161-166

THE SYNTHESIS AND THERMAL BEHAVIOR OF DICALCIUM CYCLO-TETRA- $\mu$-IMIDO-TETRAPHOSPHATE

\title{
MAKOTO SAKURAI AND MAKOTO WATANABE
}

Department of Industrial Chemistry, College of Engineering, Chubu University, Matsumoto-cho, Kasugai, Aichi 487, Japan

\begin{abstract}
$\underline{\text { Abstract }}$
Dicalcium cyclo-tetra- $\mu$-imido-tetraphosphate octahydrate has been prepared by adding aqueous calcium chloride into an aqueous cyclo-tetra- $\mu$-imidotetraphosphoric acid solution. When the cyclo-tetra- $\mu$-imido-tetraphosphate was heated, release of the water of crystallization was observed and a small decomposition of the imidophosphate occurred up to $210^{\circ} \mathrm{C}$. The imidophosphate decomposed to produce many kinds of condensed phosphates with or without $\mathrm{NH}$ and $\mathrm{NH}_{2}$ groups at a higher temperature. The sample finally changed to calcium metaphosphate .
\end{abstract}

\section{INTRODUCTION}

Phosphazenes are very famous materials for the P-N compounds. ${ }^{1-3}$ While just a few studies have been carried out for amido- and imidophosphates, because the compounds have a problem of chemical resistance. Nevertheless, amido- and imidophosphates are interesting compounds as a precursor of phosphate glass containing nitrogen, flame retardants, biochemical materials, chemical fertilizers, and so on. The present authors have published some papers on the synthesis, thermal behavior, complexation, and hydrolytic property of several amido- and imidophosphates.4-16 This paper describes the synthesis and thermal behavior of dicalcium cyclo-tetra- $\mu$-imido-tetraphosphate .

\section{EXPERIMENTAL}

\section{Preparation}

Cyclo-tetraphosphazene was dissolved in 1,4-dioxane. Sodium acetate trihydrate was dissolved in water. The solutions were warmed at $45 \sim 50{ }^{\circ} \mathrm{C}$ and then mixed. The 
mixed solution was reacted for $3 \mathrm{~h}$ at the same temperature. The white precipitate formed was quickly filtered off and washed with 70 and $90 \mathrm{v} \%$ aqueous ethanol solutions and then acetone. The product was dissolved in water. By passing through a column with a cation exchange resin, sodium ions in the solution were removed and then calcium chloride was added into the resulting solution. The white precipitate formed again was filtered off and treated with the a similar manner as above. The yield of the product was about $60 \mathrm{~mol} \%$.

\section{Analytical Techniques}

High-performance liquid chromatography(HPLC), X-ray diffractometry(XRD), ${ }^{3} 1 \mathrm{P}$ NMR measurement, and some chemical analyses were used to investigate chemical composition of a sample. Thermogravimetry(TG) and differential thermal analysis(DTA) were employed to inquire thermal property of the dicalcium cyclotetra- $\mu$-imido-tetraphosphate.

\section{RESULTS AND DISCUSSION}

\section{Chemical Composition}

The product exhibited only one HPLC peak and the result indicated that the product was a pure compound. The ${ }^{31} \mathrm{P}$ NMR spectrum of the product gave one singlet peak at $-3.3 \mathrm{ppm}$. This means that the compound has only one kind of $\mathrm{P}\left(\mathrm{O}_{2}\right) \mathrm{NH}$ group. The chemical analysis gave the contents for the product: $\mathrm{P}, 23.2 ; \mathrm{N}, 10.6 ; \mathrm{Ca}, 15.3 \%$. The calculated contents of phosphorus, nitrogen, and calcium for dicalcium cyclo-tetra$\mu$-imido-tetraphosphate octahydrate are $23.1,10.4$, and $14.9 \%$ respectively. Accordingly, it was found that the product was dicalcium cyclo-tetra- $\mu$-imidotetraphosphate octahydrate, $\mathrm{Ca}_{2}\left(\mathrm{PO}_{2} \mathrm{NH}\right)_{4} \cdot 8 \mathrm{H}_{2} \mathrm{O}$. XRD data of the product is given in Table 1. The product was stable in air at room temperature.

\section{TG and DTA Measurement}

TG and DTA curves of $\mathrm{Ca}_{2}\left(\mathrm{PO}_{2} \mathrm{NH}\right)_{4} \cdot 8 \mathrm{H}_{2} \mathrm{O}$ are given in Figure 1 . The thermal products as numbered in the figure were taken out of the furnace and served to further analysis to study thermal changes. The chemical composition of the thermal products are listed in Table 2. The first large endothermic process accompanying a rapid and large weight loss was found to be due to the release of the water of 
crystallization, because thermal product 1 was composed of only cyclo-tetra- $\mu$-imidotetraphosphate and the weight loss agreed well with the release of the water of crystallization:

$$
\mathrm{Ca} 2\left(\mathrm{PO}_{2} \mathrm{NH}\right)_{4} \bullet 8 \mathrm{H}_{2} \mathrm{O} \rightarrow \mathrm{Ca}_{2}\left(\mathrm{PO}_{2} \mathrm{NH}\right)_{4}+8 \mathrm{H}_{2} \mathrm{O}
$$

Table 1. XRD data of $\mathrm{Ca}_{2}\left(\mathrm{PO}_{2} \mathrm{NH}\right)_{4} \cdot 8 \mathrm{H}_{2} \mathrm{O}$

\begin{tabular}{crcr}
\hline $\mathrm{d}$ value $(\AA)$ & $\mathrm{I} / \mathrm{I}_{0}$ & $\mathrm{~d}$ value $(\AA)$ & $\mathrm{I} / \mathrm{I}_{0}$ \\
\hline 9.11 & 100 & 3.13 & 33 \\
8.56 & 5 & 3.04 & 11 \\
6.63 & 4 & 3.03 & 15 \\
5.49 & 23 & 2.90 & 15 \\
5.38 & 26 & 2.84 & 5 \\
5.02 & 3 & 2.75 & 10 \\
4.55 & 5 & 2.72 & 6 \\
4.25 & 6 & 2.62 & 8 \\
4.20 & 7 & 2.59 & 8 \\
4.11 & 10 & 2.56 & 10 \\
3.91 & 8 & 2.48 & 7 \\
3.67 & 6 & 2.38 & 13 \\
3.34 & 11 & 2.35 & 5 \\
3.16 & 30 & 2.28 & 8
\end{tabular}

Further, the nitrogen content of thermal product 1 was the same as that of $\mathrm{Ca}_{2}\left(\mathrm{PO}_{2} \mathrm{NH}\right)_{4}$. It can be concluded from the results that thermal product 1 was anhydrous cyclo-tetra- $\mu$-imido-tetraphosphate. Thermal product 2 contained imidophosphate with less nitrogen content than that of $\mathrm{Ca}_{2}\left(\mathrm{PO}_{2} \mathrm{NH}\right)_{4}$. It means that a part of cyclo-tetra- $\mu$-imido-tetraphosphate is decomposed. Orthophosphate and other many kinds of condensed phosphates containing or not containing amino and imino groups were present in thermal product 3 . Decomposition and reorganization of the cyclo-tetra- $\mu$-imido-tetraphosphate to those condensed phosphates were considered to occur through the step. The decomposition seemed to be caused by 


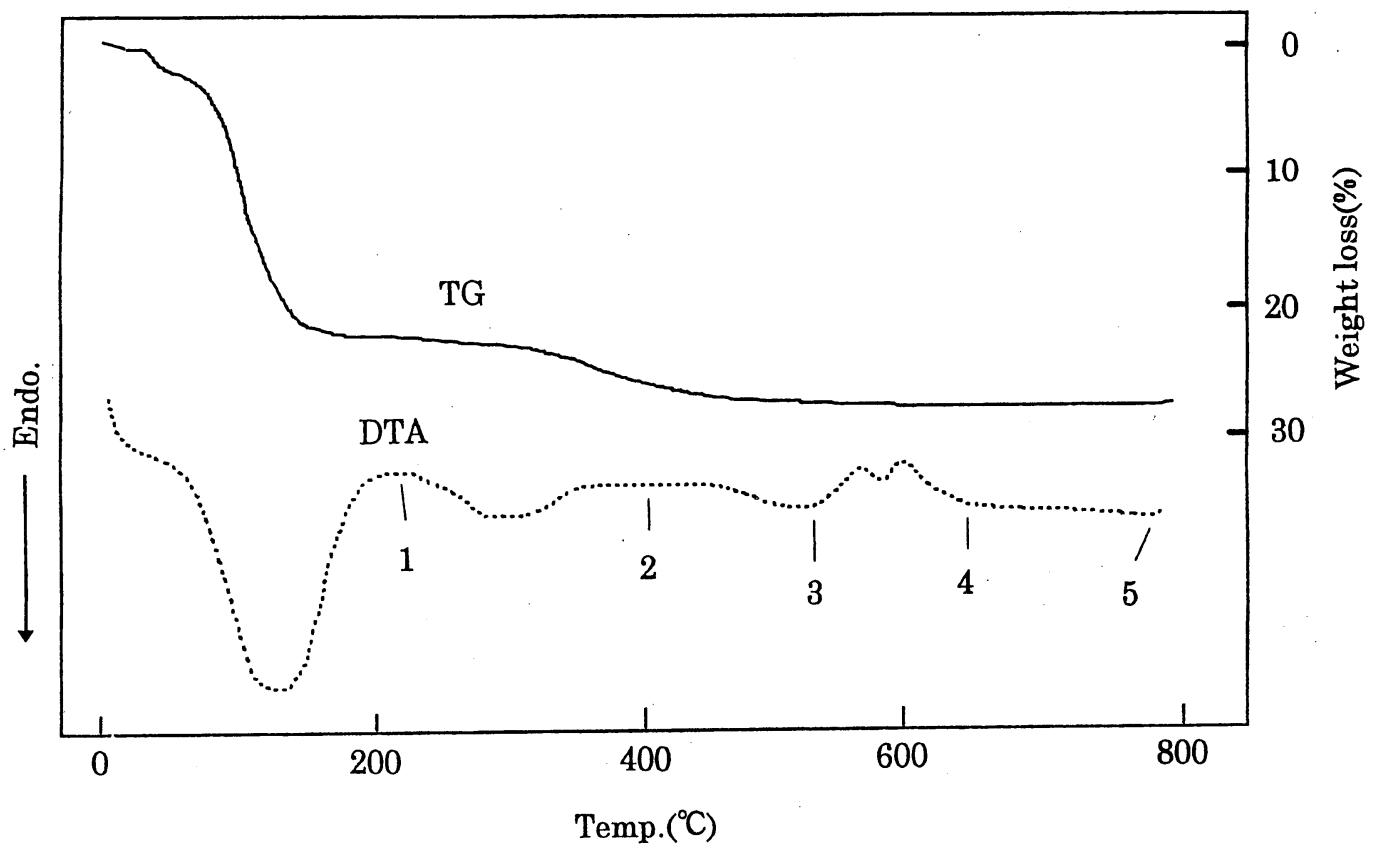

Figure 1. TG and DTA curves of $\mathrm{Ca}_{2}\left(\mathrm{PO}_{2} \mathrm{NH}\right)_{4} \cdot 8 \mathrm{H}_{2} \mathrm{O}$.

Table 2 Weight loss and composition of the thermal products.

\begin{tabular}{|c|c|c|c|c|c|c|c|}
\hline \multirow[b]{2}{*}{$\begin{array}{l}\text { Thermal } \\
\text { product }\end{array}$} & \multirow[b]{2}{*}{$\begin{array}{l}\text { Temp. } \\
\left({ }^{\circ} \mathrm{C}\right)\end{array}$} & \multirow[b]{2}{*}{$\begin{array}{c}\text { Wt.loss } \\
(\%)\end{array}$} & \multirow[b]{2}{*}{$\begin{array}{l}\text { Total } \\
N(\%)\end{array}$} & \multicolumn{4}{|c|}{ Phosphates } \\
\hline & & & & $\begin{array}{c}\text { Cyclo-tetra- } \\
\mu \text {-imido }\end{array}$ & Amido & Ortho & Others \\
\hline$-\cdots$ & $\cdots$ & $\cdots$ & 10.6 & 100 & $-\cdots$ & $\cdots--$ & $\cdots$ \\
\hline $1 *$ & 210 & 21.3 & 12.7 & 77.8 & 11.3 & 7.6 & 3.3 \\
\hline $2 *$ & 400 & 23.6 & 7.8 & 18.5 & 10.0 & 4.4 & 67.1 \\
\hline $3 *$ & 560 & 25.2 & 5.6 & -..- & 14.2 & 24.3 & 61.5 \\
\hline $4 *$ & 650 & 25.7 & 3.9 & $-\cdots$ & 23.1 & 9.6 & 63.3 \\
\hline $5 *$ & 770 & 26.0 & 3.6 & 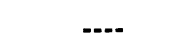 & 29.5 & 15.6 & 54.9 \\
\hline $6 *$ & 850 & 26.2 & 1.1 & $\cdots$ & ...- & 85.6 & 14.4 \\
\hline
\end{tabular}

*The samples contained a water-insoluble substance. 
water in air. The following thermal reactions can be given for the step:

$$
\begin{aligned}
& \mathrm{Ca}_{2}\left(\mathrm{PO}_{2} \mathrm{NH}\right)_{4}+\mathrm{H}_{2} \mathrm{O} \rightarrow \mathrm{CaHPO}_{3} \mathrm{NH}_{2}+\mathrm{CaH}_{3} \mathrm{P}_{3} \mathrm{O}_{9}(\mathrm{NH})_{2} \mathrm{NH}_{2} \\
& \mathrm{Ca}_{2}\left(\mathrm{PO}_{2} \mathrm{NH}\right)_{4}+(2 \mathrm{~m}-8) \mathrm{H}_{2} \mathrm{O} \rightarrow 2 \mathrm{CaH}_{2} \mathrm{P}_{2} \mathrm{O}_{\mathrm{m}}(\mathrm{NH})_{7 \cdot \mathrm{m}}+(2 \mathrm{~m}-10) \mathrm{NH}_{3}
\end{aligned}
$$

Thermal product 4 was insoluble in water. The water-insoluble thermal product can be considered to be highly polymelized condensed phosphates containing imino groups. MAS ${ }^{31} \mathrm{P}$ NMR spectra of the thermal products are given in Figure 2 . The peak at about $-10 \mathrm{ppm}$ is due to $\mathrm{P}\left(\mathrm{O}_{2}\right) \mathrm{NH}$ groups and that at about -22 ppm is given by $\mathrm{P}\left(\mathrm{O}_{2}\right)$ groups. From these results, the formation of the water-insoluble condensed phopsphates can be expressed by the equation:

$$
\mathrm{n} \mathrm{Ca} 2\left(\mathrm{PO}_{2} \mathrm{NH}\right)_{4}+\mathrm{mH}_{2} \mathrm{O} \rightarrow \mathrm{Ca}_{2 n} \mathrm{P}_{4 \mathrm{n}} \mathrm{O} \text { n }+\mathrm{m}(\mathrm{NH})_{4 \mathrm{n} \cdot \mathrm{m}}+\mathrm{mNH}_{3}
$$

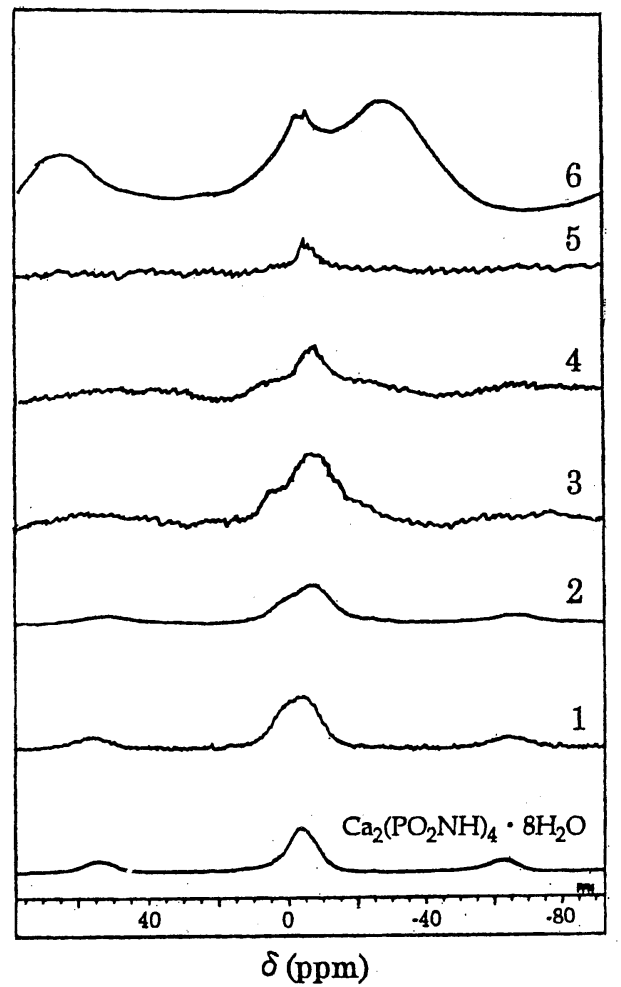

Figure 2. MAS ${ }^{31 P}$ NMR spectra of the thermal products.

At a higher temperature, the product changed to calcium metaphosphate according to the equation: 


$$
\mathrm{Ca}_{2 n} \mathrm{P}_{4 n} \mathrm{O}_{8 \mathrm{n}+\mathrm{m}}(\mathrm{NH})_{4 \mathrm{n} \cdot \mathrm{m}}+(4 \mathrm{n}-\mathrm{m}) \mathrm{H}_{2} \mathrm{O} \rightarrow 2 \mathrm{nCa}\left(\mathrm{PO}_{3}\right)_{2}+(4 \mathrm{n}-\mathrm{m}) \mathrm{NH}_{3}
$$

All of the thermal products finally converted to calcium metaphosphate in air above $850^{\circ} \mathrm{C}$. The overall reaction of the thermal change of dicalcium cyclo-tetra- $\mu$-imidotetraphosphate is explained by the equation:

$$
\mathrm{Ca}_{2}\left(\mathrm{PO}_{2} \mathrm{NH}\right)_{4}+4 \mathrm{H}_{2} \mathrm{O} \rightarrow 2 \mathrm{Ca}\left(\mathrm{PO}_{3}\right)_{2}+4 \mathrm{NH}_{3}
$$

\section{REFERENCES}

1. M. Kajiwara, Kino Zairyo, 9, 24(1989).

2. M. Kajiwara, Kino Zairyo, 11, 17(1991).

3. M. Kajiwara, Y. Yamashita, J. Mater. Sci., 26, 2797(1991).

4. M. Watanabe, S. Sato, and K. Wakasugi, Bull. Chem. Soc. Jpn.,

3, 1243(1990).

5. M. Watanabe, M. Hinatase, M. Sakurai, and S. Sato, Sekko To Sekkai, No. 232, 146(1991).

6. M. Watanabe, S. Sato, M. Sakurai, and M. Maeda, Phos. Res. Bull., 1, 143(1991).

7. M. Komiya, T. Miyajima, M. Watanabe, and S. Sato, Phos. Res. Bull., 1, 137(1991).

8. M. Watanabe, M. Sakurai, M. Hinatase, and S. Sato, J. Mater. Sci., 27, 743(1992).

9. M. Watanabe, M. Sakurai, S. Sato, and H. Mori, Sekko To Sekkai, No. 239, 245(1992).

10. M. Sakurai, M. Watanabe, Phos. Res. Bull., 2, 39(1992).

11. M. Komiya, T. Miyajima, M. Watanabe, and S. Sato, Phos. Res. Bull., 2, 33(1992).

12. M. Watanabe, S. Sato, and M. Sakurai, Sekko To Sekkai, No. 243, 117(1993).

13. M. Sakurai, M. Watanabe, Phos. Res. Bull., 3, 55(1993).

14. M. Sakurai, M. Watanabe, Bull. Chem. Soc. Jpn., 67, 1029(1994),

15. M. Sakurai, M. Watanabe, Sekko To Sekkai, No. 250, 164(1994).

16. M. Sakurai, M. Watanabe, Inorganic Mater., No. 253, 21(1994). 